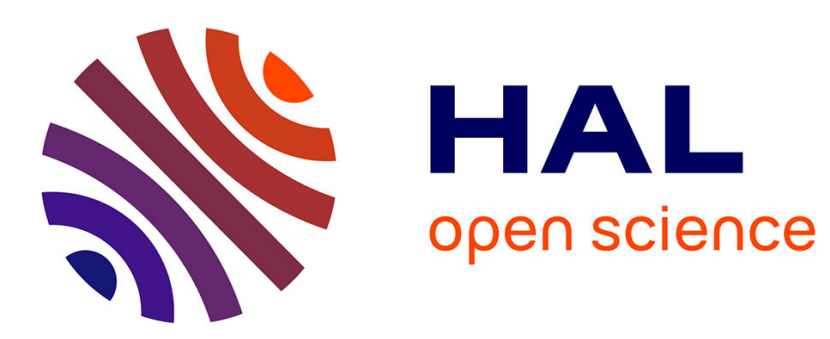

\title{
Barents Sea Monitoring with a SEA EXPLORER Glider
}

Michael Field, Laurent Béguery, Laurent Oziel, Jean-Claude Gascard

\section{To cite this version:}

Michael Field, Laurent Béguery, Laurent Oziel, Jean-Claude Gascard. Barents Sea Monitoring with a SEA EXPLORER Glider. OCEANS 2015 - Genova, IEEE/MTS, May 2015, Genova, Italy. 10.1109/OCEANS-Genova.2015.7271540 . hal-01250813

\section{HAL Id: hal-01250813 https://hal.sorbonne-universite.fr/hal-01250813}

Submitted on 6 Jan 2016

HAL is a multi-disciplinary open access archive for the deposit and dissemination of scientific research documents, whether they are published or not. The documents may come from teaching and research institutions in France or abroad, or from public or private research centers.
L'archive ouverte pluridisciplinaire HAL, est destinée au dépôt et à la diffusion de documents scientifiques de niveau recherche, publiés ou non, émanant des établissements d'enseignement et de recherche français ou étrangers, des laboratoires publics ou privés. 


\title{
Barents Sea Monitoring with a SEA EXPLORER Glider
}

\author{
Michael Field ${ }^{1}$, Laurent Beguery ${ }^{2}$, Laurent Oziel $^{1}$, Jean Claude Gascard ${ }^{1}$ \\ ${ }^{1}$ LOCEAN, UMR 7159, CNRS/UPMC/MNHN/IRD, Université Pierre et Marie Curie, Paris, France \\ ${ }^{2}$ ALSEAMAR, Meyreuil, France \\ Email: michael.field@,locean-ipsl.upmc.fr, lbeguery@alseamar-alcen.com, \\ laurent.oziel@locean-ipsl.upmc.fr, jga@locean-ipsl.upmc.fr
}

\begin{abstract}
The use of gliders in the Polar Regions offers clever and inexpensive methods for large scale monitoring and exploration. In August and September of 2014, a SEA EXPLORER glider successfully completed a $388 \mathrm{~km}$ mission in the central Barents Sea to monitor the physical and biological features over a transect between $72^{\circ} 30^{\prime} \mathrm{N}$ and $74^{\circ} 30^{\prime} \mathrm{N}$ latitude and between $32^{\circ} \mathrm{E}$ and $33^{\circ} \mathrm{E}$ longitude, as part of the European FP7 ACCESS project and in cooperation with the Institute of Marine Research, Norway.
\end{abstract}

The paper discusses the performance of the SEA EXPLORER vehicle during the mission in Arctic waters. The behavior of the magnetic compass in close proximity to the magnetic north pole is described and its resulting impact on the flight of the glider. The reliability and robustness of the vehicle is evaluated for operations in these difficult conditions. This successful and cost-effective mission now opens the door to future opportunities to conduct repeat autonomous monitoring in the Barents Sea.

\section{INTRODUCTION}

\section{A. Gliders in Our Oceans}

The use of underwater gliders in the world oceans is well established. They provide a long endurance observation platform that requires significantly reduced effort and logistics for the amount of data collected. This is particularly important in the Polar Regions, where deployment and recovery opportunities can be very limited. However, the application of gliders at high latitudes is difficult due to the challenging navigation conditions (sea ice, magnetic conditions) and cold water effects on the vehicle performance.

Gliders modified for the Arctic environment are now being used in places such as Fram Strait [1] and the Beaufort Sea [2], deployed with supporting infrastructure such as long-range acoustic beacons and moorings to allow for under-ice navigation. These successful glider experiments have involved significant cost and effort for the design and deployment of the supporting acoustic platforms.

Here we present and evaluate the use of a standard model SEA EXPLORER glider conducting monitoring in the Barents Sea without any additional supporting equipment.

\section{B. The Barents Sea}

During the last decade, which has been the warmest ever observed in the Arctic [3], climate change in the Barents Sea has been illustrated by an unprecedented decline in sea ice [4]. The Barents Sea is one of the most productive areas in

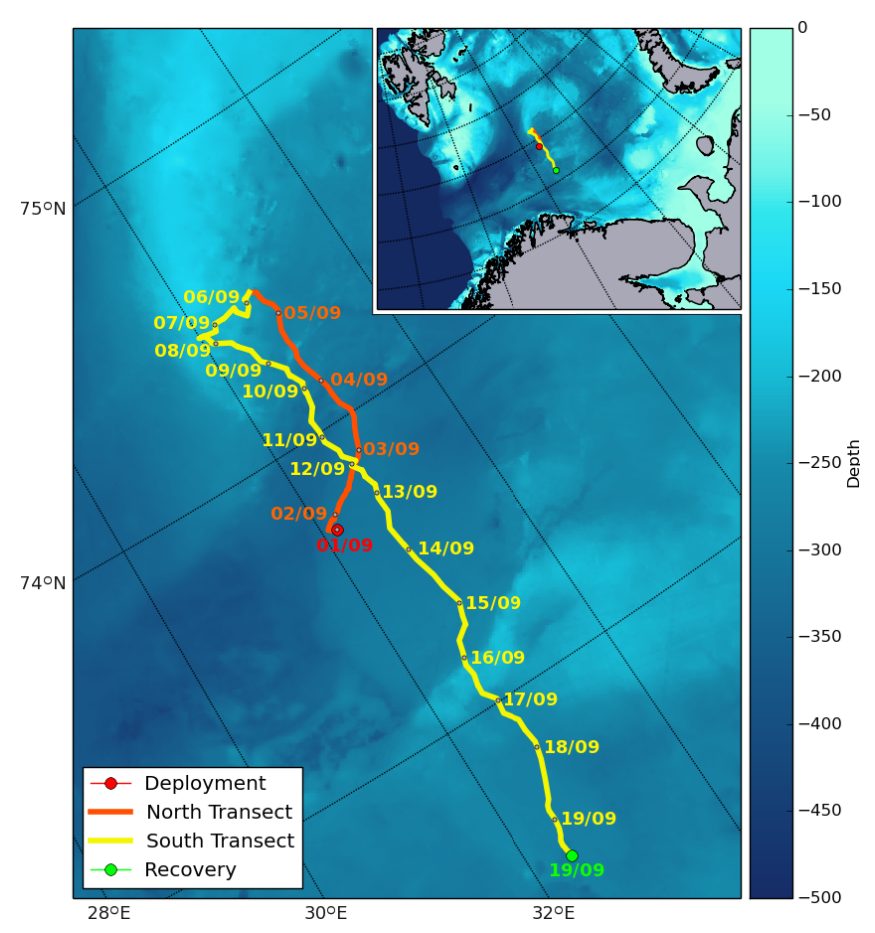

Fig. 1 Track of the SEA EXPLORER during the Barents Sea mission.

the world for fisheries and extraction of mineral resources. This is also a key area for observing exchanges between the North Atlantic Ocean and the Arctic Ocean.

The Barents Sea is a challenging operating area for a glider, with a shallow average depth of $230 \mathrm{~m}$ and banks and sea mounts rising to less than $50 \mathrm{~m}$ depth [5], in addition to strong ocean currents, in some cases with an average velocity of more than $25 \mathrm{~cm} / \mathrm{s}$ [5].

\section{Magnetic Conditions}

In 2014 the north magnetic pole was located at the approximate position of $85^{\circ} 55.56^{\prime} \mathrm{N} 148^{\circ} 49.86^{\prime} \mathrm{W}$ [6]. Approaching the magnetic north pole, the magnetic declination varies greatly over short distances and the inclination of the magnetic field approaches $+90^{\circ}$, which can result in an unstable glider-heading component when resolving the course over ground using a magnetic compass. Within the area of the Barents Sea, the magnetic declination ranges between $0^{\circ}$ and $+35^{\circ}$, while the magnetic inclination ranges between $+78^{\circ}$ and $+84^{\circ}[6]$. 


\section{The SEA EXPLORER Glider}

The SEA EXPLORER, shown in Fig. 2, is a proven underwater vehicle with a wingless design that can travel at speeds of up to $0.5 \mathrm{~m} / \mathrm{s}$. The SEA EXPLORER used for this mission - 'SEA004' - was equipped with a SeaBird pumped CTD with a SBE43 dissolved oxygen sensor, a WETLabs ECO puck fluorometer and backscattering meter, and an altimeter for sea floor detection.

Here we use a standard model of the SEA EXPLORER glider, equipped with a 3D digital magnetic compass that combines 3 -axis accelerometers with 3 -axis magnetic sensors, providing a tilt-compensated heading, pitch and roll.

\section{OPERATIONS AND PERFormance}

\section{A. Tromsø Fjords}

\section{1) Magnetic Compass Calibration}

The SEA EXPLORER glider was comprehensively tested and calibrated on land and in fjords near Tromsø, Norway, in preparation for the Barents Sea mission.

Following functional tests of the glider, the glider magnetic compass was calibrated in a clear area while suspending the SEA EXPLORER from a tree branch. Following each calibration, performance data was gathered by pitching the glider up and down while physically orientating the SEA EXPLORER in the four cardinal directions (due north, east, south and west). Fig. 3 shows an example of the performance data gathered following a calibration using approximate $\left(+/-10^{\circ}\right)$ magnetic cardinal directions, and Fig. 4 shows an example of the performance data following a calibration using precise cardinal directions.

In Tromsø, Norway, the magnetic field components include a declination of $+7.91^{\circ}$ and an inclination of $+78.35^{\circ}$ [6]. Using an approximate magnetic calibration, Fig. 3

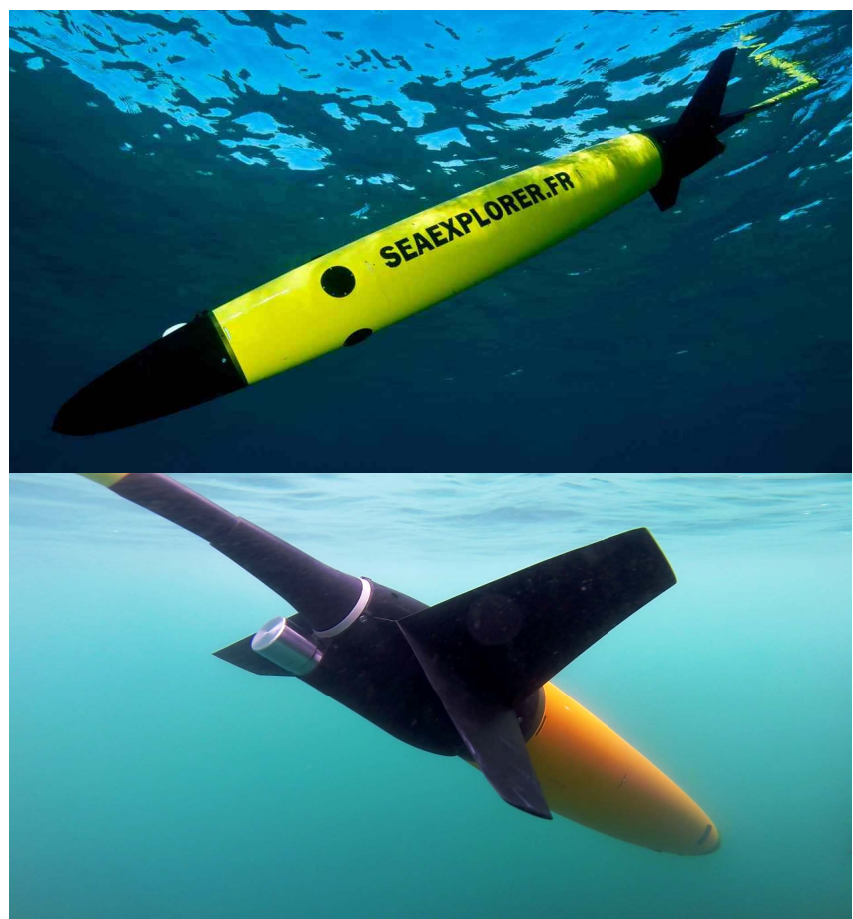

Fig. 2 The SEA EXPLORER glider, (top) in the Mediterranean and (bottom) in Balsfjorden, Tromsø.

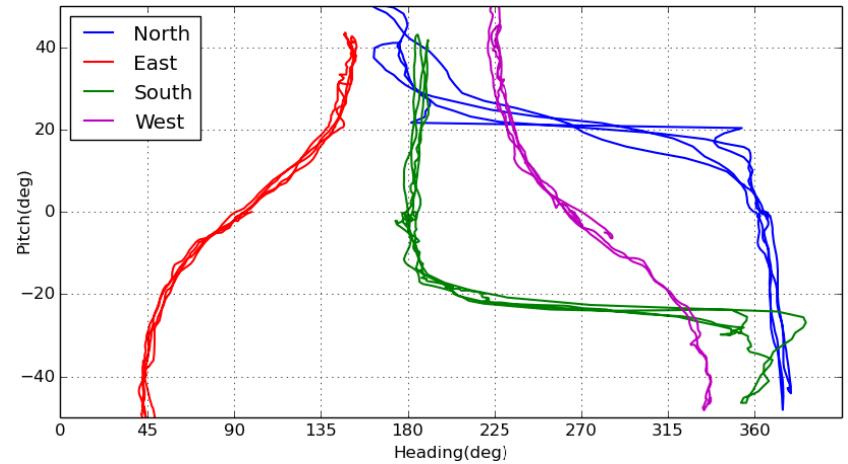

Fig. 3 Glider compass readings for fixed headings and varying pitch angles using an approximate magnetic calibration.

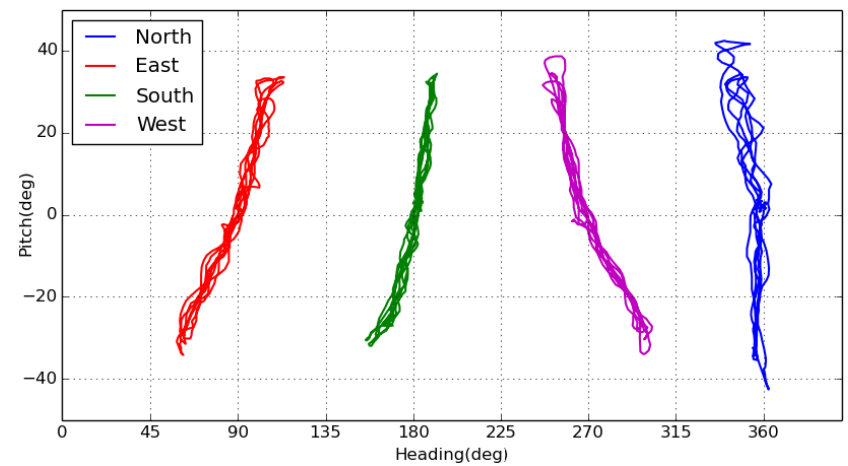

Fig. 4 Glider compass readings for fixed headings and varying pitch angles using a precise magnetic calibration.

shows that when the glider is physically heading north and pitching down, becoming more parallel to the magnetic field, the compass reliably reads a north heading. However, when the glider is pitching up, the compass reading becomes unstable between $+10^{\circ}$ to $+15^{\circ}$ pitch, approximately perpendicular to the magnetic field, and then shifts by $180^{\circ}$ beyond $+20^{\circ}$ pitch, crossing the point of being perpendicular to the magnetic field and resolving the glider heading component in the opposite direction. The inverse behavior is observed when the glider is physically heading south, with the $180^{\circ}$ shift in compass reading occurring when pitching down beyond $-20^{\circ}$ pitch, again crossing the point of being perpendicular to the magnetic field. It is also observed that during the $180^{\circ}$ shift for both north and south physical headings, the compass readings tend to the west during each shift. When the glider is physically heading due east or due west, the compass reading shifts consistently around the physical heading point, from $45^{\circ}$ towards the north when pitching down, to $45^{\circ}$ towards the south when pitching up, in each direction shifting towards alignment with the heavily inclined magnetic field.

The performance data in Fig. 3 can be used as an example of how to fly the glider in conditions where the compass calibration no longer precisely matches the local magnetic field. For example, when heading north, it would be best to limit the surfacing pitch angle to $+10^{\circ}$ to avoid the glider compass reading shifting by $180^{\circ}$ to a heading of south, which would result in the glider rolling to try to turn to the north when it is already heading north. The same can be seen when heading south, to limit the diving pitch angle to $-10^{\circ}$. The easterly and westerly errors are relatively 
consistent and could be taken into account to explain any deviations in heading that might not be explained by water currents.

For the mission in the Barents Sea, the digital compass was precisely calibrated to the magnetic conditions of Tromsø, resulting in a much improved performance of the glider compass for a full range of heading and pitch angles, as shown in Fig. 4. However, this performance was limited to the Tromsø area and its local magnetic conditions, differing to those expected along the Barents Sea monitoring track $\left(+15^{\circ}\right.$ to $+18^{\circ}$ declination, $+79^{\circ}$ to $+82^{\circ}$ inclination [6]), as the compass could not be re-calibrated while at sea. The results of this precise calibration show that the compass is able to compensate for the high inclination angle in Tromsø using information from the $3 \mathrm{D}$ accelerometer. A declination offset of $+16^{\circ}$ was included in the calibration to compensate for the approximate expected declination along the Barents Sea track.

\section{2) 24-hour Fjord Mission}

To demonstrate the ability of the SEA EXPLORER to navigate in challenging magnetic conditions, a 24-hour mission was successfully completed using the approximate calibration of Fig. 3 in the northern section of Balsfjorden, a fjord south of Tromsø. The mission area of Balsfjorden has a north-south orientation and is between $2 \mathrm{~km}$ to $4 \mathrm{~km}$ wide, with a maximum depth of $120 \mathrm{~m} \mathrm{[7].}$

Piloting the glider from Tromsø, the pitching angles were adjusted to reduce the instability of the magnetic compass and evaluate its performance as the glider travelled northward and southward along the fjord. The SEA EXPLORER was deployed at 0813UTC on 15 August and recovered at $0855 \mathrm{UTC}$ on 16 August, completing a $15.3 \mathrm{~km}$ track of repeating north-south transects in shallow waters, shown in Fig. 5.

This successful test mission proved that the SEA EXPLORER could be safely piloted in challenging magnetic compass conditions based on the information gathered from the testing on land, in preparation for the mission in the Barents Sea.

\section{B. Barents Sea Monitoring}

\section{1) Operations Overview}

The deployment of the SEA EXPLORER SEA004 glider was made possible with the help of the Institute of Marine Research, Norway, providing the opportunity to participate in the 2014 Mareano 3 expedition, departing from Tromsø 18 August 2014.

The SEA004 glider was deployed for mission M120 on 1 September 2014 from the rescue boat of the R/V GO SARS at a position of $73^{\circ} 42.92^{\prime} \mathrm{N} 32^{\circ} 9.77^{\prime} \mathrm{E}$ in the central Barents Sea, as shown in Fig. 1. The glider first travelled north over five days (north transect), gradually compensating for a strong current pushing the glider to the east, reaching a northernmost position of $74^{\circ} 29.03^{\prime} \mathrm{N} 32^{\circ}$ $45.85^{\prime} \mathrm{E}$. The glider then travelled west for two days before travelling south for the remaining eleven days (south transect), again gradually compensating for a current pushing the glider to the east. The SEA004 glider was recovered on 19 September 2014 , with $40 \%$ available battery

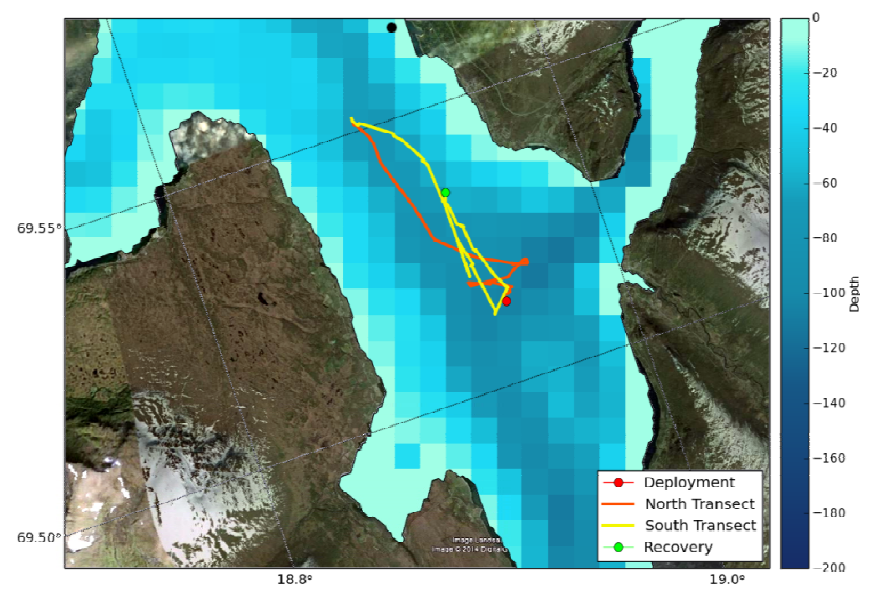

Fig. 5 SEA EXPLORER track of the 24-hour test mission in Blasfjorden.

power remaining, in challenging conditions (Sea State 6) by the R/V Johan Hjort at a position of $72^{\circ} 28.41^{\prime} \mathrm{N} 32^{\circ} 26.15^{\prime}$ E, successfully completing a track of $388 \mathrm{~km}$.

\section{2) Magnetic Compass Performance}

The magnetic compass performed reasonably well throughout the mission in the Barents Sea. The compass occasionally had difficulty at the northernmost latitudes of the track, furthest from the magnetic calibration conditions, and quickly improved when moving south towards the Norwegian coast. The pitching angles of the glider were adjusted throughout the mission, based on the performance data gathered in Tromsø. As a result, the glider flew with low pitch angles during the north transect $\left(+/-12^{\circ}\right)$ and

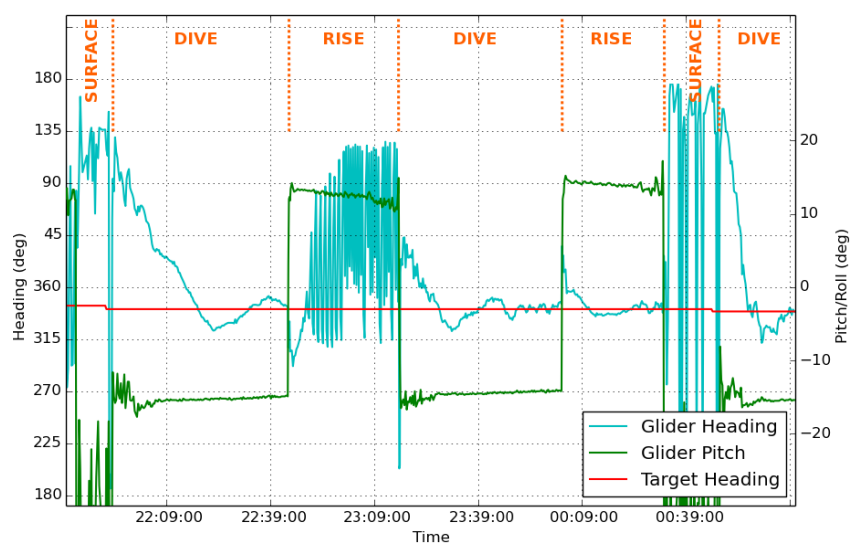

Fig. 6 Magnetic heading rapid $180^{\circ}$ oscillation when pitching up.

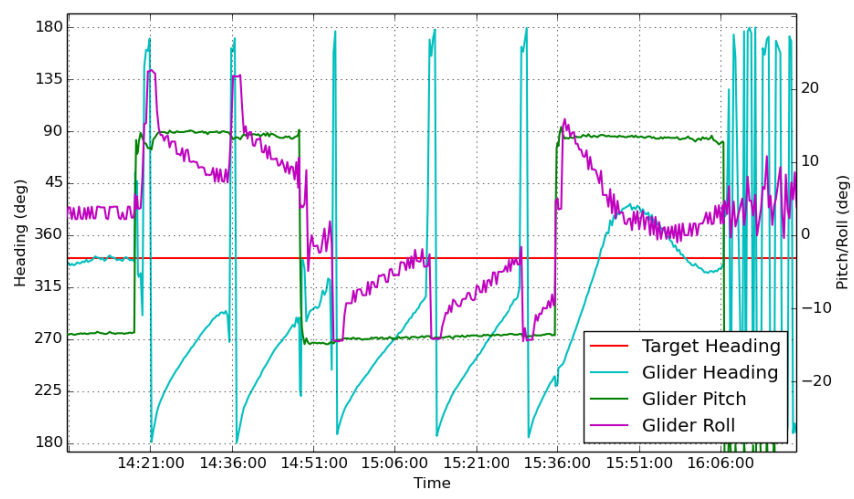

Fig. 7 Magnetic heading $180^{\circ}$ shift and resulting glider roll. 
increased following improved behavior during the south transect $\left(+/-20^{\circ}\right)$.

During the north transect, with the glider heading north and gradually compensating for local currents, the magnetic compass occasionally showed two types of bad behavior.

The first, shown in Fig. 6, occurred when heading north and pitching up, placing the glider compass perpendicular to the magnetic field, resulting in an noisy reading that oscillated rapidly by up to $180^{\circ}$. This occurred during $20 \%$ of the pitching up cycles during the north transect and would normally be rectified by the pitching down section that followed.

The second type of bad behavior, shown in Fig. 7, also occurred when heading north and pitching up, resulting in a stable shift of $180^{\circ}$ that the glider then tried to correct by rolling. This repeats several times, during both pitching up and pitching down, as the glider attempts to reach the correct heading by rolling either left or right. It is noted that the heading readings tend to the west, as was observed with the approximate calibration in Tromsø, regardless of whether the glider rolls left or right. This occurred on another $20 \%$ of cycles during the north transect, and would normally be rectified within 2 cycles.

During the south transect, the magnetic compass readings improved significantly, exhibiting the described bad behavior on less than $1 \%$ of the total cycles. Fig. 8

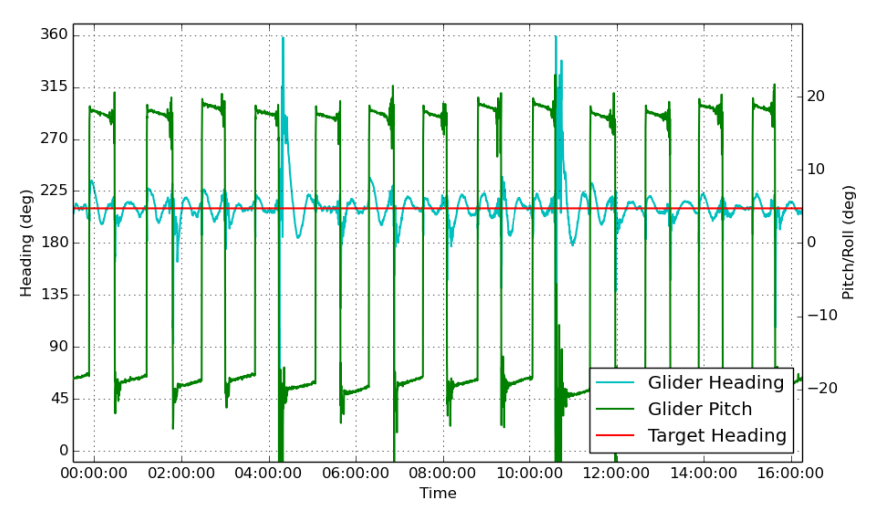

Fig. 8 Magnetic heading during south transect.

shows an example of the magnetic heading during several cycles of the south transect.

3) Bathymetry

The altimeter was initially disabled to conserve power and was to be enabled once approaching the shallow central bank. On 4 September, the glider unexpectedly surfaced with an alarm triggered from making contact with the sea floor at $143 \mathrm{~m}$ depth, $50 \mathrm{~m}$ shallower than known bathymetry [8] and nautical charts [7] for this location, which show a narrow ridge in the area that has a minimum depth of $\sim 200 \mathrm{~m}$. The contact with the muddy sea floor is confirmed by a temporary offset in salinity and dissolved
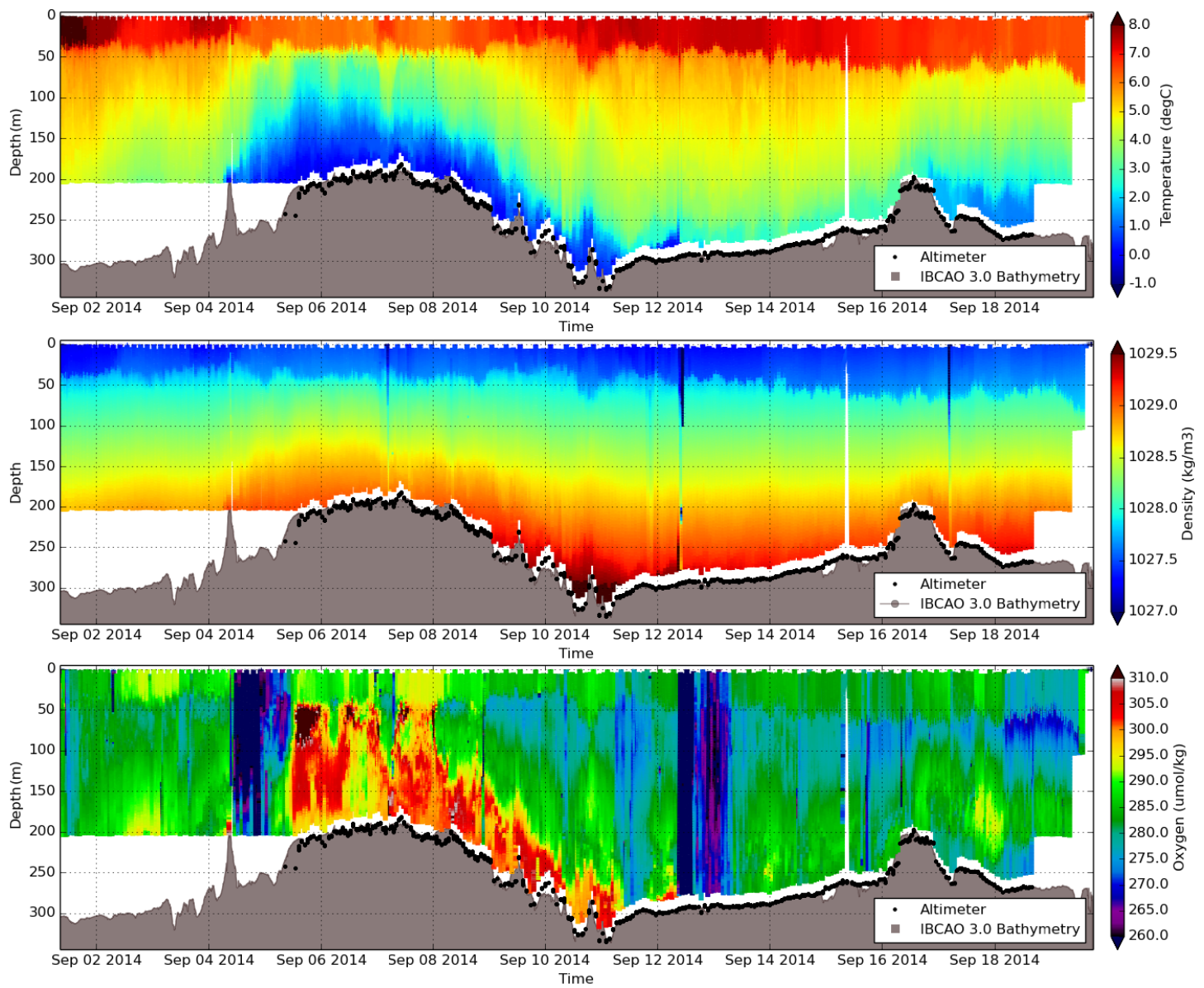

Fig. 9 SEA004 temperature, salinity, density and dissolved oxygen data during the Barents Sea monitoring mission. 
oxygen readings, indicating sediment in the CTD tubing, which dissipated over the cycles that followed. The softsurface contact is also confirmed by the glider attitude parameters which show a stable heading, pitch and roll during the event: the glider gently coming to a stop, holding position briefly, then a clean change in pitch to ascend to the surface in response to the alarm conditions.

\section{4) Science Payload}

The high quality temperature, salinity, oxygen, chlorophyll and depth data was successfully recorded and sent in real-time during surfacing periods, some examples of which are shown in Fig. 9.

The dissolved oxygen plot shows two occasions where sediment or other material entered the sampling tubing, resulting in a temporary offset in measurements. The first event occurred following the contact with the sea floor, and the second event occurred during the south transect. The salinity readings are briefly affected at the beginning of each event and quickly rectify. Following recovery of the glider, it was noted that a slight constriction in the sensor tubing near the inlet of the oxygen sensor, downstream of the salinity sensor, may have caused some sediment trapping or build-up and resulting in the longer duration oxygen offset.

The initial profiles closely agreed with ship-based CTD casts taken near the deployment location, as shown in Fig. 10. The difference in the readings at $35-45 \mathrm{~m}$ depth is partly due to the variation of the depth of the fresh-water surface layer, as well as thermal inertia and hysteresis of CTD sensors.
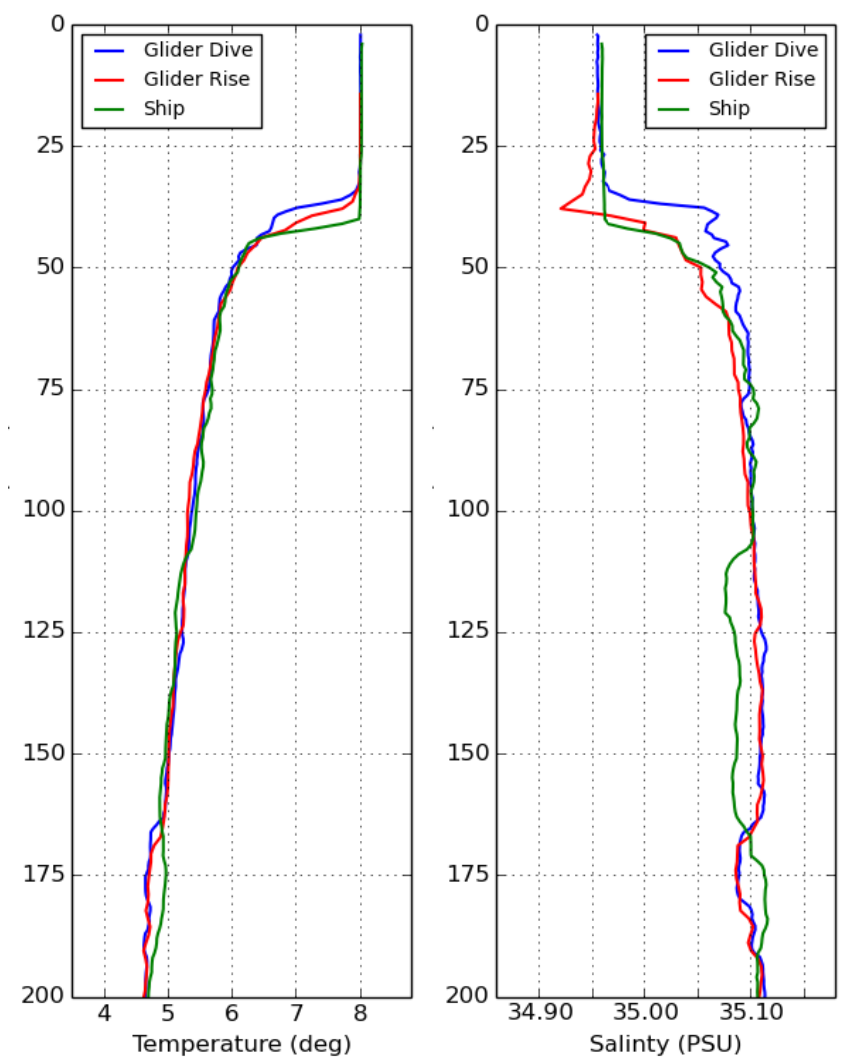

Fig. 10 Comparison between ship and glider CTD readings at time of deployment (separation of $2.5 \mathrm{~km}$ and 2 hours).

\section{CONCLUSION}

This successful mission in the Barents Sea provided excellent high-resolution data in this remote location with significantly reduced cost and effort. The mission also provided, along with the testing in the Tromsø fjord, detailed information on how to operate the SEA EXPLORER in these challenging conditions, as well as identifying opportunities for improvement, such as economizing the use of the largest power consumers (expected update in early 2015) and endurance testing of the battery pack in cold water conditions.

Another area of active development is to improve the behavior and reliability of the glider magnetic compass in the Polar regions. It is feasible to conduct the compass calibration while deployed at sea; implementing a controlled set of movements while recording magnetic values that can then be used for a re-calibration of the magnetic compass. This could be performed several times during a mission and account for the significant differences in magnetic conditions along the track, resulting in improved behavior and overall efficiency of the glider.

This mission has proven the robust ability of the SEA EXPLORER glider in this environment, and opens the door to future opportunities to conduct autonomous monitoring in the Barents Sea and key Arctic shelf seas.

\section{ACKNOWLEDGMENT}

The authors would like to thank Dr. Anne Helene and the Institute of Marine Research, Norway, as well as the crews of the $\mathrm{R} / \mathrm{V}$ GO SARS and $\mathrm{R} / \mathrm{V}$ Johan Hjort for their assistance and cooperation. The research leading to these results has been supported by ACCESS (Arctic Climate Change, Economy and Society), with funding from the European Union under Grant Agreement $n^{\circ} 265863$ within the Ocean of Tomorrow call of the European Commission Seventh Framework Programme.

\section{REFERENCES}

[1] Lee, C., et al. "Autonomous platforms in the arctic observing network." Proceedings of Ocean Obs09: Sustained Ocean Observations and Information for Society 2 (2010).

[2] Lee, Craig M., et al. Marginal Ice Zone (MIZ) Program: Science and Experiment Plan. No. APL-UW-1201. WASHINGTON UNIV SEATTLE APPLIED PHYSICS LAB, 2012.

[3] Stocker, Thomas F., et al. "Climate change 2013: The physical science basis." Intergovernmental Panel on Climate Change, Working Group I Contribution to the IPCC Fifth Assessment Report (AR5)(Cambridge Univ Press, New York) (2013).

[4] Comiso, Josefino C., et al. "Accelerated decline in the Arctic sea ice cover." Geophysical Research Letters 35.1 (2008).

[5] Loeng, Harald. "Features of the physical oceanographic conditions of the Barents Sea." Polar research 10.1 (1991): 5-18.

[6] Maus, Stefan, et al. "The US/UK world magnetic model for 20102015." (2010).

[7] Norwegian Mapping Authority, Kartverket Norwegian Nautical Charts: General Chart Series, No.300 INT10 (2009), No.514 INT 174 (2011).

[8] Jakobsson, M., et al. (2012), The International Bathymetric Chart of the Arctic Ocean (IBCAO) Version 3.0, Geophysical Research Letters, doi: 10.1029/2012GL052219. 